\title{
Construcción de una dogmática constitucional del procedimiento parlamentario: El caso colombiano*
}

\author{
Leonardo García Jaramillo**
}

\begin{abstract}
RESUMEN
Este artículo reconstruye los principales precedentes de la Corte Constitucional Colombiana en materia de control al procedimiento parlamentario y los analiza respecto del vicio de inconstitucionalidad por elusión deliberativa. Estos precedentes establecen un sólido criterio de constitucionalidad que puede servir como referente acerca del tipo, fundamento y forma de ejercicio del control constitucional en los países de la región. A partir de principios constitucionales, normas reglamentarias, precedentes horizontales y doctrina constitucional, se ha construido una dogmática constitucional del procedimiento parlamentario que se ha estructurado a partir del ideal deliberativo de la democracia en la dimensión de su justificación epistémica.
\end{abstract}

Derecho constitucional - jurisprudencia - democracia deliberativa - legitimidad procedimiento parlamentario

\section{Construction of a constitutional dogmatic for the parliamentary process: The Colombian case}

\begin{abstract}
This article reconstructs the main precedents of Colombian Constitutional Court respect to the control towards parliamentary procedure and analyzes it in the light of unconstitutionality defect in which it is incurred when a project suffers from deliberative avoidance. These precedents have become a solid criterion of constitutionality that might serve as a reference about the type, foundation and manner of exercise of constitutional control in the region. From constitutional principles, rules, horizontal precedent and constitutional doctrine, the Court has built a constitutional dogmatic of parliamentary procedure that has been structured from the ideal of deliberative democracy in the dimension of his epistemic justification.
\end{abstract}

Constitutional law - jurisprudence - deliberative democracy - legitimacy parliamentary procedure

* La primera versión de este trabajo se impartió como conferencia en el I Congreso Internacional de Derecho Constitucional y Filosofía Política. Belo Horizonte (Brasil) nov. 4 a 7 de 2014. Presenta resultados de la tesis de maestría en humanidades, con énfasis en estudios políticos, defendida en la Universidad EAFIT (Colombia) en 2014. Agradezco a mi director, Mauricio García Villegas, así como a Carlos Bernal, Roberto Gargarella, Rodolfo Arango y Miguel Carbonell, su orientación en los temas centrales de esta investigación. Agradezco también a los dos árbitros anónimos por sus rigurosas observaciones, estilísticas y metodológicas.

** Abogado. Magíster en Humanidades Universidad EAFIT, Colombia y estudiante de posgrado, Università Degli Studi Di Genova, Italia. Correo electrónico: 1garciaj@eafit.edu.co.

Artículo recibido el 18 de marzo de 2015 y aceptado para su publicación el 21 de enero de 2016. 


\section{INTRODUCCIÓN}

$\mathrm{E}$ n su prolija jurisprudencia, la Corte Constitucional Colombiana, además de legislación negativa, ha tomado decisiones que han hecho a Colombia un país interesante en términos de derecho comparado ${ }^{1}$. Se ha argumentado que la Corte es el tribunal judicial más poderoso del mundo, incluso respecto de la Corte Suprema de los Estados Unidos ${ }^{2}$, asimismo que supone el punto de inflexión que marca el inicio y establece las bases para el desarrollo de una forma constitucional propia durante las dos últimas décadas en Latinoamérica. Uno de los asuntos que ha merecido particular atención por parte de la Corte, y a partir del cual se puede reconstruir una doctrina jurisprudencial, es la exigencia al respeto por los procedimientos constitucionales y legales en la conformación de la voluntad mayoritaria, tanto respecto de leyes como de actos legislativos (reformas a la Constitución). En concreto, dentro de tales procedimientos la salvaguarda a la deliberación parlamentaria reviste particular interés, porque se trata de la etapa donde se someten a consideración las iniciativas que aspiran a convertirse en normas y políticas. Se debaten, controvierten y reformulan los proyectos para alcanzar mayores consensos y, así, mayor legitimidad y efectividad. La etapa propiamente deliberativa, previa a la votación, cuenta con unos presupuestos particularmente importantes para realizar el principio democrático y para proteger el diseño de la forma de gobierno establecido por el Constituyente en 1991. En una democracia constitucional y dentro de un ordenamiento jurídico constitucionalizado, la garantía efectiva de los principios constitucionales que son resguardados por la normativa procedimental, tanto las reglas constitucionales como las normas reglamentarias, cuenta tanto al nivel de la validez jurídica intrasistémica como de la legitimidad política extrasistémica.

En este artículo se analizan las principales sentencias que ha proferido la Corte donde ha reivindicado los principios y valores exigidos por una concepción deliberativa de la democracia. A partir de la conocida distinción teórico-jurídica entre disposición y norma, el aspecto más relevante al momento de determinar estándares de constitucionalidad construidos a partir de disposiciones legales y constitucionales, más que su texto mismo, son las decisiones en donde dichas disposiciones se han interpretado y se ha prescrito lo que prohíben, permiten u ordenan ${ }^{3}$. Se sustenta que tanto por la consagración de disposiciones constitucionales y legales, como particularmente por

${ }^{1}$ Véanse las contribuciones en J. C. Henao (ed.), Diálogos constitucionales con el mundo. Bogotá: Universidad Externado - Corte Constitucional, 2013.

2 D. Landau, "Political Institutions and Judicial Role in Comparative Constitutional Law", en Harvard International Law Journal. Vol. 51, $\mathrm{N}^{\circ} 2,2010$.

${ }^{3}$ Una disposición es el conjunto de palabras, de enunciados lingüísticos, contenidos en los artículos de una ley o de la Constitución, tal como fueron adoptados por la institución con la autoridad para hacerlo. Las disposiciones de derecho fundamental son los enunciados de la Constitución que establecen los derechos fundamentales. Una norma es el conjunto de significados atribuibles a las disposiciones. La norma proviene entonces del significado del enunciado lingüístico mediante la interpretación y establece las proposiciones prescriptivas que se adscriben a las disposiciones. Véase, Robert Alexy, Teoría de los derechos fundamentales. Madrid, Centro de Estudios Constitucionales, $2^{\text {a }}$ ed., 2007, cap. 2, II. 
el desarrollo que en su implementación en polémicos casos concretos ha realizado la jurisprudencia de la Corte Constitucional, en Colombia se ha consagrado un modelo deliberativo de democracia. En particular, la jurisprudencia ha hecho una interesante lectura local de la justificación epistémica de la democracia deliberativa. Ha sustentado que el procedimiento democrático deliberativo es respetuoso de valores sustantivos. El procedimiento político determinado por la deliberación otorga legitimidad a las decisiones que resultan del mismo, porque es el más confiable en términos de probabilidad para alcanzar decisiones correctas. El valor epistémico de la democracia deliberativa radica en que el procedimiento político, enmarcado por valores sustantivos y principios constitucionales, permite a los participantes en la conformación de la voluntad general, llegar a un conocimiento acerca de la verdad moral. En el proceso de dotar de sentido a las disposiciones constitucionales y legales respecto del procedimiento parlamentario, la Corte ha incorporado argumentos provenientes de una concepción deliberativa de la democracia, en particular, por una concepción epistémica. La concepción deliberativa de la democracia en su dimensión epistémica concibe a la democracia de forma profundamente articulada con la moralidad y confía en su poder para transformar las preferencias de las personas en preferencias moralmente aceptables. "La prueba que debe satisfacer una decisión para ser aprobada a través de los procedimientos democráticos, es la misma que debe satisfacer una proposición que aspire a ser reconocida como verdadera desde el punto de vista moral" ${ }^{\text {. }}$

Los precedentes relativos al vicio de inconstitucionalidad en el que se incurre cuando un proyecto de ley o de reforma constitucional adolece de elusión deliberativa, se ha constituido en un sólido criterio de constitucionalidad que, además, está en capacidad de servir como referente de derecho comparado acerca del tipo, fundamento y forma de ejercicio del control constitucional en los países de la región. En este trabajo se reconstruye la línea jurisprudencial que sintetiza coherentemente el fundamento de las decisiones que se han tomado. El estudio de los precedentes es esencial para estructurar la naturaleza del derecho como una empresa racional guiada por la razón práctica 5 . La Corte ha construido una dogmática del procedimiento parlamentario a partir de la cual puede reconocerse que la concepción democrática de los constituyentes y la que ha reivindicado la Corte en su jurisprudencia, es la deliberativa. Con esta dogmática la Corte ha desarrollado, respecto del procedimiento parlamentario de aprobación de leyes y actos legislativos, los principios constitucionales que consagran el carácter democrático, pluralista, transparente e incluyente del Estado colombiano. La dogmática constitucional estabiliza los argumentos y la interpretación del derecho. Este tipo de dogmática se concibe como un grupo de conceptos y categorías en los que se sostiene el derecho constitucional y a partir de los cuales se estructura. Conforme a tales conceptos y su interpretación el derecho adquiere coherencia interna ${ }^{6}$.

${ }^{4}$ C. S. Nino, The Constitution of Deliberative Democracy. New Haven, Yale University Press, 1996, p. 143.

${ }^{5}$ N. Mac Cormick, R. Summers (eds.), Interpreting Precedents: A comparative study. Dartmouth, 1997, p. 6.

${ }^{6}$ M. Aragón Reyes, "Las singularidades de la interpretación constitucional y sus diferencias respecto de la interpretación de la ley”, en J. C. Henao (ed.), Diálogos constitucionales de Colombia con el mundo. Op. cit. 
Debido a que el Reglamento del Congreso contiene requerimientos de orden técnico y operativo que en su trabajo ordinario los congresistas utilizan de forma más bien pragmática y estratégica, ha sido la jurisprudencia constitucional la encargada de armonizarlas y adaptarlas a las condiciones de la deliberación que pueden ser entendidas esencialmente según los postulados deliberativos establecidos por las disposiciones constitucionales y las normas reglamentarias. La subregla que ha establecido el requisito formal y material de la deliberación en las decisiones legislativas, procura irradiar con los postulados constitucionales y avances jurisprudenciales los mecanismos de trámite de las leyes y los actos legislativos.

\section{CONSTITUCiONALismo COLOMBiANO Y MODELO DELIBERATIVO} DE LA DEMOCRACIA

Dos razones sustentan que el constitucionalismo colombiano adopta un modelo deliberativo de democracia. La primera es de carácter normativo-procedimental: el reglamento del Congreso y la propia Constitución consagran reglas que se deben respetar durante el trámite para que un proyecto se convierta en ley o en reforma constitucional, las cuales, además de regular el trámite legislativo en concreto, protegen la garantía de principios constitucionales inescindiblemente ligados con el modelo deliberativo. La segunda es de naturaleza jurisprudencial: numerosos precedentes instituidos por la Corte Constitucional han establecido como criterios de control constitucional el respeto a los principios y valores que resguarda la normativa reglamentaria, tales como, de un lado, los principios constitucionales en general: el principio de representación, el pluralismo político, la igualdad, la democracia participativa, la dignidad humana, la protección de minorías y la participación de los ciudadanos en las decisiones que los afectarán; y, de otro lado, los principios del trámite parlamentario en particular: identidad, consecutividad, unidad de materia y el principio democrático. Estos principios son presupuestos de la actividad legislativa y la conformación del poder político ${ }^{7}$.

El ordenamiento jurídico colombiano consagra diversa normativa relativa a los derechos y principios que, en el marco de una democracia constitucional, se deben garantizar durante el trámite parlamentario de leyes y actos legislativos, con el objetivo de preservar los elementos esenciales de la Constitución o, como ha dicho la Corte, los "elementos que le confieren la identidad"8, tales como: el sistema de frenos y contrapesos institucionales, la máxima validez normativa otorgada a los derechos fundamentales, el principio de igualdad, el goce efectivo de los derechos, los derechos fundamentales de las minorías y la oposición, el respeto por las reglas de juego electoral, los controles interinstitucionales entre las ramas del poder público y el presupuesto de que entre los poderes del Estado debe haber un equilibrio. A partir de la normativa reglamentaria que ampara

\footnotetext{
${ }^{7}$ Sentencia C-252 de 2012.

${ }^{8}$ Sentencia C-243 de 2012.
} 
los principios constitucionales, la jurisprudencia ha establecido varias reglas concretas que se deben respetar durante dichos trámites para no incurrir en vicios insubsanables.

Los precedentes han amparado la regla de mayorías al verificar que aconteció una libre oportunidad de deliberación para todos los congresistas en igualdad de condiciones, al verificar que la expresión de las mayorías es la que queda consagrada en la norma porque no se presentaron manipulaciones, procedimientos ocultos ni acuerdos perversos para hacer avanzar un proyecto en su trámite parlamentario. Los precedentes han amparado también la regla de minorías que garantiza el derecho de las minorías a ser representadas, a participar y a expresarse. La línea jurisprudencial que se ha seguido desde las primeras sentencias que profirió la Corte sobre los efectos de los vicios relacionados con la falta de deliberación, ha desarrollado esta normativa vigorizando y articulando su contenido, y estableciendo criterios claros que orientan la labor del Congreso como máximo órgano representativo, el que resulta además el órgano con la conformación y los procedimientos para erigirse como el escenario idóneo para realizar las deliberaciones en virtud de las cuales se tomen las grandes decisiones nacionales.

\section{LÍNEA JURISPRUDENCIAL SOBRE OPORTUNIDAD DE DELIBERACIÓN EN EL PROCEDIMIENTO PARLAMENTARIO}

\subsection{Debate, deliberación y votación}

La estructuración del precedente respecto de elusión deliberativa en la versión que conocemos ahora, comenzó por otorgar gran importancia al debate parlamentario, el que no corresponde a la mera realización de una votación que concluye una discusión informal acerca del proyecto en general. En este sentido, la jurisprudencia debió precisar y materializar la disposición legal y constitucional que consagra la obligatoriedad del debate durante el trámite parlamentario de los proyectos de ley y de reforma constitucional. En la sesión de debate se exige la posibilidad de deliberar concerniente a la materia del proyecto como paso previo a la votación, lo que se demuestra en la exigencia de dos tipos de quórum: el deliberatorio y el decisorio?. El debate es la oportunidad de hacer efectivo el principio democrático porque posibilita la intervención y la expresión de minorías en el proceso de formación normativa ${ }^{10}$.

${ }^{9}$ La Corte ha reiterado la diferencia entre quórum deliberatorio y quórum decisorio. En deliberatorio es el número mínimo de miembros de la respectiva comisión o cámara que deben estar presentes en el recinto para que la unidad legislativa pueda discutir atinente a los temas objeto de su atención. Si se verifica este quórum no implica necesariamente que se pueda adoptar una decisión determinada, pues para ello se exige el quórum decisorio que corresponde al número mínimo de miembros de la comisión o cámara que deben estar presentes durante todo el proceso de votación. Así es como las cámaras y sus comisiones no pueden abrir sesiones ni deliberar con menos de una cuarta parte de sus miembros y solo se pueden tomar decisiones con la asistencia de la mayoría (mitad más uno) de la respectiva corporación. Art. 145 constitucional. Sentencia C-008 de 1995.

${ }^{10}$ Sentencias C-222 de 1997 y C-760 de 2001. 
Puede que haya habido la respectiva sesión de debate pero que no haya habido deliberación. Sobre todo puede que haya habido votación sin deliberación, por lo que la jurisprudencia diferencia entre estos dos momentos y establece que uno es prerrequisito de validez jurídica del otro. La deliberación del proyecto y su votación son dos instancias diferentes. La deliberación implica el intercambio de ideas y razonamientos en pro o en contra de los proyectos presentados. La votación es la conclusión de un tipo de debate desarrollado sobre la base de la discusión libre y en igualdad de condiciones entre todos los facultados para intervenir y sobre el supuesto de la suficiente ilustración en el seno de la respectiva comisión o cámara. Es inherente al debate la exposición de ideas, criterios y conceptos diversos, así como la confrontación y el examen de las distintas posibilidades y la consideración colectiva, razonada y fundada, acerca de las repercusiones que habrá de tener la decisión puesta en tela de juicio ${ }^{11}$.

La votación debe resguardarse como una etapa posterior y distinta de la deliberación dentro de la sesión de debate. La primera es el acto colectivo en el que los miembros de la Corporación declaran su voluntad acerca de la iniciativa discutida. La deliberación comporta la oportunidad de discutir el proyecto puesto a consideración del Congreso. Ambas instancias deben cumplirse a cabalidad para que pueda entenderse válido el proceso de aprobación de las leyes ${ }^{12}$. Cualquier proposición (modificatoria, aditiva o supresiva) presentada en el curso de los debates se debe deliberar y votar, a menos que sean retiradas definitivamente por su autor.

Si un determinado artículo no es objeto de deliberación, bien sea porque se introduce en una sesión posterior o porque hacía parte de un proyecto, se retira y luego se vuelve a incorporar, adolece de elusión deliberativa y por tanto es forzosa su inconstitucionalidad $^{13}$. La votación no es la esencia del debate sino la discusión y la controversia del legislador ante la conformación normativa. Al eludir la deliberación se viola de forma flagrante el deber constitucional (art. 157) y legal (arts. 176 y 227 del reglamento del Congreso) de debatir suficientemente los proyectos y, así, de permitir la intervención de los parlamentarios, el gobierno por intermedio de los ministros y la ciudadanía ${ }^{14}$.

\subsection{Principio de instrumentalidad de las formas}

El principio de instrumentalidad de las formas, que deriva del artículo 228 constitucional donde se estipula la primacía de lo sustancial sobre lo formal, consagra que las reglas procedimentales, dentro de las que se encuentran las disposiciones del procedimiento legislativo, están al servicio de fines sustantivos. Su observancia no es un fin en sí mismo. Las normas que regulan la aprobación de leyes y actos legislativos no carecen de relevancia, sino que vinculan la importancia de las formas procesales a

\footnotetext{
11 Sentencia C-222 de 1997.

12 Sentencia C-1147 de 2003.

13 Por ejemplo, sentencia C-1147 de 2003.

${ }^{14}$ Sentencia C-668 de 2004.
} 
los objetivos y valores constitucionales que protegen, en lugar que a sus propias estipulaciones. Incluso si se violan normas reglamentarias durante el trámite de formación de una ley, no se incurre necesariamente en un vicio de inconstitucionalidad. Para que una violación reglamentaria implique una declaratoria de inconstitucionalidad debe involucrar la vulneración de un requisito exigido por la Constitución para el trámite de los proyectos de ley ${ }^{15}$.

En consonancia con el principio de instrumentalidad, los vicios en el procedimiento legislativo no necesariamente implican la declaratoria de inconstitucionalidad de la norma cuyo proceso no fue impecable. En estos casos se observa si la irregularidad impide en efecto la realización del elemento sustancial protegido por la forma. Si acontece una irregularidad procesal por quebrantamiento de los requisitos legales que protegen el proceso de formación de la voluntad democrática en el Congreso, pero no subsiste como consecuencia la afectación del elemento sustancial, no debe proceder la declaratoria de inconstitucionalidad. La jurisprudencia ha precisado en este sentido que no toda afectación a una norma contenida en el Reglamento del Congreso, o incluso a una norma constitucional sobre el trámite parlamentario de los proyectos, comporta un vicio insubsanable que acarree declaratoria de inconstitucionalidad. La forma en el caso concreto debe interpretarse entonces desde un punto de vista teleológico respecto del fin sustantivo al que sirve el elemento formal, que puede ser un derecho, valor o principio (igualdad, debido proceso, publicidad, debida conformación de la voluntad democrática de las cámaras, regla de minorías, principio democrático, pluralismo, etc.) ${ }^{16}$.

Se puede tratar de una irregularidad irrelevante si no vulnera ningún principio ni valor constitucional, y si no afecta el proceso de formación de la voluntad democrática ni desconoce el contenido básico institucional reconocido en la Constitución. A pesar del vicio, puede haberse cumplido con el objetivo protegido por la norma procesal o igualmente se pudo haber convalidado durante el trámite parlamentario. Si por la irregularidad efectivamente cometida se declara inconstitucional la norma, terminaría siendo más traumático para el ordenamiento en un momento determinado que no hacerlo si se verifica que no se vulneró ningún principio ni valor constitucional. Las irregularidades que implican vicios insubsanables son las que vulneran algún principio o valor constitucional, afectan el proceso de formación de la voluntad democrática o desconocen las competencias y estructura institucional diseñada por la Constitución ${ }^{17}$. Cuando la Corte encuentra vicios procedimentales subsanables en la formación del acto sujeto a su control, ordenará devolverlo a la autoridad que lo profirió para que lo enmiende. Subsanado el vicio, procederá a decir sobre la exequibilidad del acto ${ }^{18}$.

La flexibilización del trámite de las leyes establecida en 1991 respecto de la Constitución de 1886 no significa que los vicios en el procedimiento de formación

\footnotetext{
${ }^{15}$ Ibídem.

${ }^{16}$ Sentencia C-872 de 2002 y Auto 029A de 2002.

${ }^{17}$ Sentencias C-240 de 2012 y C-737 de 2001.

${ }^{18}$ Art. 241 constitucional.
} 
hayan perdido importancia según la posibilidad de que en algunos casos acarreen la declaratoria de inconstitucionalidad de la norma que los haya presentado ${ }^{19}$. Las normas que regulan la aprobación de leyes y actos legislativos no tienen la función de obstaculizar o impedir la expedición de leyes, ni mucho menos de dificultar la deliberación en condiciones de libertad e igualdad entre los facultados para hacerlo, como ordena la normativa constitucional, lo que equivaldría a desconocer la primacía de lo sustancial sobre lo procedimental ${ }^{20}$.

\subsection{Publicidad de proyectos y de convocatorias a sesiones}

Un elemento esencial de la posibilidad de una debida deliberación durante las sesiones de debate, sobre todo las primeras, que a su vez está ligado con la deliberación parlamentaria como requisito esencial para la validez y legitimidad de las decisiones, es la publicación oportuna de la ponencia de los proyectos. Esta publicación condiciona el desarrollo del debate por parte de los congresistas en la medida en que la distribución de una copia del correspondiente documento es esencial para que los miembros de una respectiva célula legislativa puedan conocer el mismo ${ }^{21}$.

Las funciones del Congreso, principalmente proferir leyes y actos legislativos, nombrar algunos funcionarios públicos y ejercer el control político, solo pueden cumplirse respetando los principios constitucionales. Cuando las iniciativas se vierten en la política se debe honrar la publicidad en todos los momentos del procedimiento legislativo. Es una condición de legitimidad de la discusión parlamentaria y de igual forma contribuye tanto al accountability parlamentario para que se pueda exigir el cumplimiento del debate y el respeto a los principios constitucionales que procuran resguardar de las posiciones egoístas, parcializadas y autointeresadas como al mantenimiento de canales comunicativos abiertos para la preservación de una sociedad en la que las posiciones políticas mayoritarias y minoritarias circulen con libertad e igualdad de concisiones en la arena política.

En la sentencia C-951 de 2001, declaró inconstitucional la ley 620 de 2000 que aprobaba la suscripción de la Convención Interamericana sobre restitución internacional

19 Sentencias C-500 de 2001 y C-026 de 1993.

20 Sentencia C-055 de 1996. En la sentencia C-872 de 2002 la Corte declaró exequible la ley 643 de 2001 que fija el régimen del monopolio rentístico de juegos de suerte y azar. Presuntamente se habían incumplido requisitos formales como un error en la Gaceta del Congreso sobre la fecha de la sesión en la cual se aprobó el proyecto de ley. Se probó que no se habían violentado principios constitucionales. El error en la fecha que se publicó correspondió a un error de transcripción. Publicar una fecha incorrectamente configura un vicio insubsanable solo si compromete algún principio constitucional o tiene efectos sustantivos.

${ }^{21}$ Sobre la finalidad de la publicación de ponencia, la Corte ha tratado diversos casos como por ejemplo en las sentencias C-951 de 2001 y C-1250 de 2001: en la primera se dijo que el desconocimiento de la exigencia de publicar previamente en la Gaceta del Congreso las ponencias para primer debate no representa una irregularidad menor sino que configura un vicio de procedimiento, y en la segunda se debió intervenir en un enfrentamiento entre el Ejecutivo y el Legislativo por la conveniencia y por la constitucionalidad de un proyecto de ley. 
de menores, debido a que acontecieron dos irregularidades en el trámite en el Senado: la ponencia para primer debate se publicó después de su aprobación en la Comisión segunda y en el expediente no aparece ninguna constancia de que la ponencia para primer debate en la Cámara haya sido publicada en la Gaceta del Congreso ${ }^{22}$.

Desde sus primeras sentencias ha insistido la Corte en el punto de la publicidad, la que cumple ciertamente la importante finalidad de la transparencia de los debates que se dan en el Legislativo, al racionalizar la discusión, permitir que la decisión sea más propensa a considerar los distintos intereses sociales, con ello las deliberaciones conducen efectivamente a que se produzcan resultados más justos e imparciales. En la sentencia C-386 de 1996 se demandó la constitucionalidad de un extenso y variado articulado de la ley 5 ta de 1992 para cuya resolución la Corte acudió a distintos argumentos constitucionales, legales y jurisprudenciales ${ }^{23}$.

En particular en el examen a la constitucionalidad del artículo 88 la Corte abordó tres asuntos directamente relacionados con el ideal deliberativo, como son las formas de contar con una democracia más amplia, la opinión pública y la igualdad entre las ramas del poder en materia informativa. Para que pueda hablarse verdaderamente de una democracia constitucional, es esencial que la actividad parlamentaria esté regida por los principios de transparencia y publicidad que son condiciones de legitimidad de la deliberación en la medida en que visibilizando las discusiones es que los congresistas pueden cumplir sus funciones, particularmente la de traducir políticamente la opinión de los distintos grupos y sectores de la sociedad ${ }^{24}$. La publicidad conduce a la transparencia y estas a la imparcialidad, esencial en el grado de justicia que ostente una decisión y cardinal en el modelo deliberativo de la democracia ${ }^{25}$. En una democracia participativa, además, tienen que honrarse los principios que conectan a los parlamentarios con sus electores.

Uno de los requisitos mínimos de racionalidad deliberativa y decisoria es que los congresistas conozcan el texto sometido a votación con suficiente antelación, lo que desde la sentencia C-760 de 2001 se constituye en un criterio necesario para superar el examen constitucional. Esta sentencia, que declaró constitucional el Código Penal ${ }^{26}$, desarrolló y amplió la ratio de la sentencia C-222 de 1997, pues sostuvo que la regulación del proceso de formación de las leyes, como una de las funciones esenciales del Congreso en donde participa la Corte, y en particular la oportunidad de deliberación

${ }^{22}$ La ley 5 de 1992 (art. 156) consagra una alternativa para agilizar el trámite de un proyecto que consiste en que el presidente de la comisión respectiva puede autorizar la distribución de la ponencia de forma previa al debate entre los miembros de la comisión. La ponencia se debe publicar de todas formas después en la Gaceta, pero la verificación de la distribución previa salva la constitucionalidad de una norma si se publicó en la Gaceta después de aprobada.

${ }^{23}$ Respecto de la doctrina de la sustitución constitucional, esta sentencia enfatiza que el Congreso no es la máxima autoridad institucional ni puede operar como tal porque constituye un poder constituido.

${ }^{24}$ La sentencia cita a Kant, quien consideraba que uno de los principios trascendentales del derecho público era el que "son injustas todas las acciones que se refieren al derecho de otros hombres cuyos principios no soportan ser publicados”.

${ }^{25}$ La sentencia C-386 de 1996 es citada por la sentencia C-915 de 2001 a este preciso respecto.

${ }^{26}$ Ley 600 de 2000. 
dentro de la sesión de debate, es la oportunidad de hacer efectivo el principio democrático y procuran igualmente proteger el diseño de la forma de gobierno establecido por el Constituyente. La Corte encontró en la sentencia C-760 de 2001 que la ley era constitucional pero declaró contrarios a la Constitución algunos artículos y apartes que no fueron publicados en la Gaceta $\mathrm{N}^{\circ} 540$ de 1999, y que no fueron hechos públicos por otro medio, ni fueron conocidos por la Plenaria de la Cámara. Además el proyecto existente se modificó de forma significativa en materias como la jurisdicción indígena, que "se sujetará a la ley que regule la materia", pero ni siquiera se consultó con dicha minoría étnica.

Además del vicio por vulneración de los principios de identidad y consecutividad, la Corte declaró inconstitucionales, en sentencia C-141 de 2010, la ley convocatoria a un referendo constitucional para permitir la segunda reelección presidencial porque la convocatoria a sesiones extra y su reunión se dio sin que el Decreto correspondiente fuera publicado en el Diario Oficial, por lo que no existía sustento jurídico que autorizara la reunión y por tanto la sesión extraordinaria debió ser declarada nula.

La falta de publicidad implica naturalmente el desconocimiento general del proyecto o de la proposición que lo modifica, lo que excluye la posibilidad de su deliberación y vicia irremediablemente su votación. Mientras que el conocimiento previo por parte de los parlamentarios de los proyectos de ley y de las modificaciones propuestas a los mismos, constituye el acatamiento de un supuesto mínimo de racionalidad deliberativa y decisoria exigido como requisito constitucional en el trámite parlamentario de aprobación de una ley ${ }^{27}$. Acerca del principio de publicidad la Corte ha regulado que los informes de las comisiones deben ser conocidos por las plenarias de las cámaras antes de ser sometidos a aprobación, pues sin el conocimiento previo no es posible entender que el debate y la decisión realmente existieron ${ }^{28}$.

\section{4. "No taxation without Representation" y racionalidad deliberativa}

Uno de los criterios fundamentales que ha usado la Corte para considerar inconstitucional una reforma tributaria es la presentación oportuna del articulado al inicio del trámite para no vulnerar la debida deliberación que, en materias sensibles como el aumento de impuestos, debe preceder a la aprobación de leyes tributarias. La deliberación es entonces la que materializa la representación conforme al principio de la "no tributación sin representación”. La representación de los sectores sociales se manifiesta gracias a la posibilidad de deliberación parlamentaria, así que con incumplirla no solo se afecta la normativa reglamentaria sobre formación de leyes sino también el principio de legalidad del tributo. El respeto al supuesto político de la representación se corresponde con la necesidad de un acto del legislador para la creación de gravámenes. La creación

\footnotetext{
${ }^{27}$ Sentencia C-688 de 2002.

${ }^{28}$ Sentencia C-179 de 2002.
} 
de impuestos exige el consentimiento de la colectividad ${ }^{29}$ y, por tanto, exige un respeto al trámite parlamentario y, en particular, la satisfacción de un mínimo de racionalidad deliberativa respecto de las implicaciones de la modificación para los principios tributarios y, en últimas, para la sociedad.

La Corte ha reafirmado el amplio margen de configuración que la Constitución le confiere al Congreso en materia de política tributaria, con el fin de que pueda determinar qué no se grava, qué se grava y con qué porcentaje. Este margen de configuración ha sido calificado como "la más amplia discrecionalidad" 30 . De la particular amplitud no se deriva, claramente, la falta de límites. Como todo ejercicio que realice el Congreso en el marco de una democracia constitucional, está sometido a los límites y vínculos que establecen los derechos fundamentales y los principios constitucionales que, como la legalidad tributaria, la equidad fiscal, la eficiencia, la progresividad y la igualdad real, debe respetar la potestad impositiva del Congreso. El Congreso puede modificar la normativa tributaria en ejercicio de esta potestad, pero no lo puede hacer de cualquier forma.

En sentencia C-776 de 2003 la Corte encontró inconstitucional una disposición de una ley que reformaba el estatuto tributario ${ }^{31}$. La disposición, entre otras normas, consagraba la inclusión de nuevos productos como objeto de impuesto al valor agregado (IVA) y la ampliación del porcentaje que se tributaba por otros productos. Se ampliaba la base del IVA a productos de primera necesidad como la leche, la carne, los huevos y los medicamentos, así como a servicios esenciales como la salud, el agua, la luz, el gas y la educación, que se gravaban con $2 \%$. La Corte también fundamentó la inconstitucionalidad de la disposición en un vicio por elusión deliberativa. Tuvo en cuenta en parte información relacionada con las tasas de pobreza e indigencia, la equidad del sistema tributario, los niveles de desescolaridad y desempleo, así como la distribución del ingreso en Colombia, y la falta de medidas de gasto social efectivas que compensen la afectación del mínimo vital de las personas más necesitadas ${ }^{32}$.

Debido a que el IVA es un impuesto indirecto, es regresivo, toda vez que se debita a las personas con independencia de su capacidad económica. Si bien la Corte había señalado que se presume la capacidad de pago de quienes adquieren productos grabados, este criterio no vincula este caso porque se trata de productos de primera necesidad que por su naturaleza requieren todos los miembros de la sociedad, pero cuyo impuesto solo afecta a los más desfavorecidos que tienen capacidad de pago reducida ${ }^{33}$. Tampoco se deriva que siempre y en todos los casos los impuestos indirectos sean declarados inconstitucionales, pero indica que debe examinarse el contexto socioeconómico en el que van a implementarse los nuevos gravámenes.

\footnotetext{
${ }^{29}$ Sentencia C-1383 de 2000.

30 Sentencia C-007 de 2002.

${ }^{31}$ Ley 788 de 2002 "por la cual se expiden normas en materia tributaria y penal del orden nacional y territorial; y se dictan otras disposiciones”.

32 Sentencia C-776 de 2003, apartado 4.5.6.1.

33 Sentencia C-505 de 1999.
} 
La manera como se configuró la disposición en el Congreso omitió el principio de consecutividad porque fue introducido en el penúltimo debate durante las deliberaciones en la plenaria de la Cámara y, como no tenía unidad de materia con el resto del articulado, constituía un tema nuevo que debía haber surtido los cuatro debates reglamentarios. Como el Senado no tuvo ocasión de conocerlo, se introdujo mediante comisión de conciliación. Un tema nuevo, y particularmente sensible ${ }^{34}$, se incluyó en el resto del articulado, de forma tal que no pudo ser debatido. No solo de la concepción de la disposición sino también de la forma como fue incorporada al proceso parlamentario, se establece que fue el resultado de una decisión arbitraria de gravar un alto número de bienes y servicios diversos ${ }^{35}$, la cual se tomó sin el mínimo de deliberación parlamentaria exigido por el principio de legalidad del tributo, es decir, de que no puede haber tributación sin la debida representación.

A pesar de que había razones constitucionales de fondo para pronunciarse sobre la inconstitucionalidad de ampliar la base gravable del IVA a productos de primera necesidad, porque afectaba principios constitutivos del modelo de Estado social y democrático de derecho, la razón de la decisión en este caso fue que la decisión se tomó sin respeto a los principios que resguardan las normas que regulan el trámite de las normas en el Congreso y eludiendo, en consecuencia, la deliberación acerca de las implicaciones de dicha ampliación respecto de los principios de progresividad y equidad ${ }^{36}$. Un mínimo de racionalidad deliberativa debe preceder la decisión de ampliar la base gravable del IVA a productos de primera necesidad, máxime cuando deliberaciones anteriores habían sostenido la conveniencia de no hacerlo ${ }^{37}$.

${ }^{34}$ Se dice en la sentencia que el ejercicio de la potestad impositiva del Estado no puede estar encaminado a empujar a los estratos bajos hacia la pobreza y a los pobres hacia la indigencia. La Corte ha señalado desde sus primeras sentencias que corresponde al legislador velar por la "efectiva idoneidad" de los sujetos obligados por las normas tributarias, de tal manera que no se impongan cargas sobre personas cuyo nivel de ingresos "se agota en la satisfacción de sus necesidades vitales mínimas". Sentencia C-776 de 2003 , apartados 4.5.3.2.2.2 y 4.5.3.3.2.

35 Desde armas de fuego y maquinaria hasta leche y huevos.

36 "Estos principios constituyen los parámetros para determinar la legitimidad del sistema tributario y se predican del sistema en su conjunto y no de un impuesto en particular". Sentencia C-643 de 2002. La Corte protege la sujeción del poder tributario a los mandatos constitucionales, por ello debe asegurarse que el sistema tributario se enmarque en los principios de justicia y equidad, los cuales se concretan en las fórmulas de reparto de la carga tributaria y en la adecuada distribución del gasto público. Sentencia C-183 de 1998.

${ }^{37}$ Para declarar inconstitucional el artículo 116 se tuvo en cuenta también la vulneración al derecho fundamental del mínimo vital en tanto garantía de la dignidad humana en su dimensión de "vivir bien" con condiciones mínimas de vida sin las cuales las personas no tienen un mínimo de calidad de vida. Con la probada afectación al sector más desfavorecido de la población, que ha aumentado como se sabe por cifras respecto de pobreza y desigualdad, no es equiparable automáticamente la capacidad para adquirir bienes y servicios, con capacidad contributiva. De los bienes y servicios de primera necesidad gravados depende el goce efectivo del derecho al mínimo vital. El deber general de contribuir a financiar los gastos del Estado se debe ponderar con principios de justicia y equidad. "No se puede afirmar que quien agota todo su ingreso en adquirir lo necesario para subsistir, tiene una capacidad contributiva reflejada en su posibilidad de adquirir bienes y servicios que ineludiblemente debe comprar para sobrevivir". Sentencia C-776 de 2003. 


\subsection{Elusión deliberativa por falta de "consulta previa"}

Conforme a una concepción deliberativa de la democracia se deben promover y fortalecer mecanismos para reducir el autointerés egoísta en la formación de la voluntad general y para contribuir a depurar el trámite parlamentario de la lógica perversa que muchas veces lo regula mediante la observancia al principio de publicidad, por ejemplo. Las medidas legislativas o administrativas que afectan derechos de pueblos étnicos minoritarios no se toman necesariamente por la lógica perversa del capital, sino por el desconocimiento de sus preferencias y necesidades. La misma falibilidad humana es un criterio para promover los mecanismos que contribuyan a tomar decisiones en las cuales se logre una adecuada articulación entre la necesidad de explotar los recursos naturales y la protección que el Estado le debe dispensar a la integridad social, cultural y económica de las comunidades, es decir, que permitan lograr una ponderación correcta entre los principios que ampara el derecho a la consulta previa, de un lado, y el principio a la seguridad jurídica y el derecho al desarrollo económico, por otro.

En virtud de la ratificación del Convenio 169 de la Organización Internacional del Trabajo (OIT) “sobre pueblos indígenas y tribales en países independientes”, se estableció un estándar de constitucionalidad basado en el derecho de tales comunidades a participar en la formulación, aplicación y evaluación de los programas de desarrollo nacional y regional que probablemente les afectaran de manera directa (art. 7). El objetivo de la consulta es determinar la eventual afectación directa que podrían sufrir estos grupos por la implementación de una medida legislativa (expedición de normas que los involucren o los afecten) o administrativa (expedición de una licencia ambiental para explotar recursos naturales $)^{38}$.

Este tratado internacional es reconocido en virtud del artículo 330 constitucional $^{39}$ y forma parte del bloque de constitucionalidad ${ }^{40}$ debido a su aprobación en Colombia por la Ley No 21 de 1991. La Corte ha utilizado la consulta como un estándar de constitucionalidad para proteger principios como autonomía, integridad e identidad cultural y económica de los pueblos indígenas y tribales. La Corte ha declarado inconstitucionales

${ }^{38}$ Sentencia T-382 de 2006. Otras sentencias en las cuales se ha decidido sobre el derecho a la consulta previa, son: sentencias T-428 de 1992 (resguardo indígena de Cristianía en el caso de la troncal del café), SU-039 de 1997 (pueblo indígena U’wa), T-652 de 1998 (pueblo Indígena Embera Katio), C-169 de 2001 (circunscripción electoral de las comunidades negras), C-891 de 2002 (consulta en la expedición del Código de Minas), SU-383 de 2003 (fumigaciones que afectaban pueblos indígenas y tribales de la Amazonía) y T-880 de 2006 (cabildo Motilón Bari en caso de perforación exploratoria de Ecopetrol).

${ }^{39}$ Otros artículos constitucionales que respaldan la figura de la consulta previa, son: 1, 2, 7, 70, 93 y 329. Normas constitucionales relacionadas son aquellas que protegen las garantías otorgadas a los pueblos indígenas, tales como las integradas en los artículos 10 (las lenguas y dialectos de los grupos étnicos son oficiales en sus territorios), 68 (derecho a la identidad cultural), 96 (los indígenas asentados en territorios fronterizos son nacionales por adopción), 171 (circunspección especial indígena con dos senadores que los representen), 246 y 330 (autonomía judicial y gubernamental), 286 y 329 (territorios indígenas como entes territoriales) y 330, parágrafo (derecho de participación de los pueblos indígenas).

${ }^{40}$ Sentencia T-606 de 2001. 
diversas normas porque durante el trámite parlamentario no se cumplió con la consulta previa a los pueblos indígenas y grupos étnicos. Más que por su ratificación formal, el Convenio se ha constituido entonces en un estándar para determinar la validez de normas en Colombia por cuenta de su implementación por parte de la Corte. Lo ha elevado a estatus iusfundamental porque está ligado a la subsistencia del grupo como grupo humano y como cultura. Es un derecho fundamental de carácter colectivo que procura proteger la integridad cultural, social y económica de grupos minoritarios, y asimismo amparar su derecho a la participación. Su realización debe estar enmarcada en un proceso público en el que se garantice el debido proceso (principio de oportunidad, comunicación intercultural y bilingüismo). La consulta se debe realizar de manera previa a la adopción de la medida para que precisamente la participación de las comunidades les permita contribuir en su configuración ${ }^{41}$. El derecho a preservar la integridad de la comunidad se garantiza mediante el ejercicio del derecho a la participación en la adopción de las decisiones administrativas y legislativas que puedan afectarles.

Se ha establecido la existencia de dos dimensiones del derecho de participación de los pueblos indígenas: el derecho general de participación y el deber de consulta. Conforme al primero los Estados deben crear medios para que se haga efectivo el derecho de los interesados a participar en la adopción de las medidas que los van a afectar. La normativa constitucional que lo respalda es básicamente la igualdad política, la participación en el procedimiento legislativo y la circunspección especial. Conforme al deber de consulta, el Estado está obligado a realizarla, toda vez que se constituye en un derecho fundamental ${ }^{42}$. Se configura una violación a la Constitución si se pretermite en el trámite legislativo por el claro vínculo entre la realización de la consulta y la protección de la identidad cultural de las minorías étnicas ${ }^{43}$. La Corte reconoce el derecho a la deliberación autónoma para que libremente convoquen a sus integrantes y representantes y valoren las ventajas y desventajas del proyecto ${ }^{44}$. La participación debe ser real y efectiva tratándose de las cuestiones que afectarán a las comunidades, sobre todo en casos de explotación de recursos naturales en sus territorios. La participación no se emula con una simple función informativa y la realización de la consulta debe estar regida por el principio de la buena fe. Tres criterios existen entonces en el estudio del deber de realizar la consulta en cada caso: (i) la obligatoriedad, (ii) las características de la obligatoriedad, y (iii) las consecuencias de su pretermisión u omisión ${ }^{45}$.

${ }^{41}$ La sentencia SU-039 de 1997 estableció los criterios para la realización de la consulta. La sentencia C-030 de 2008 precisó la forma de realización de la consulta.

42 Sentencia C-615 de 2009.

43 Sentencia C-615 de 2009. La sentencia C-175 de 2009 establece las reglas que se deben cumplir en la manera de realizar la consulta.

${ }^{44}$ Sentencia SU-039 de 1997.

45 Sentencias C-030 de 2008 y C-461 de 2008. En esta última sentencia se declaró exequible la Ley No 1151 de 2007, contentiva del Plan Nacional de Desarrollo 2006-2010, condicionadamente a la suspensión de la ejecución de los proyectos o presupuestos plurianuales que tengan la potencialidad de incidir directa y específicamente sobre pueblos indígenas o comunidades étnicas afrodescendientes, hasta que se realice la 
Dos casos pusieron en la agenda de discusión nacional el control que ejerce la Corte a la manera como se elaboran las normas en el Congreso cuando se elude la deliberación respecto de las comunidades indígenas o étnicas que se verán afectadas por su implementación. En ambos casos se declararon inconstitucionales medidas, defendidas con especial vigor por el gobierno de entonces, que omitieron durante sus respectivos trámites de formulación y expedición el requisito de la consulta a las comunidades indígenas y tribales a pesar de afectarles directamente. Se trata de la ley forestal (Ley N ${ }^{\circ} 1021$ de 2006) ${ }^{46}$ y del estatuto de desarrollo rural (Ley $\mathrm{N}^{\circ} 1152$ de 2007) ${ }^{47}$. Las razones por las cuales se reconoció que, en el caso del estatuto de desarrollo rural, se había violado el deber de realizar la consulta previa, fueron el reconocimiento de la importancia que para la definición de su propia identidad tiene la regulación de la propiedad agraria en la que se encuentran asentadas las comunidades indígenas, y la obligatoriedad del deber de consulta se refuerza por la existencia de materias que específicamente regulan temas relacionados con las comunidades indígenas o afrodescendientes.

La consulta previa tiene unas características que no se pueden sustituir durante el proceso participativo ordinario del Congreso, ya que en el mismo no hay oportunidad de que las comunidades conozcan el proyecto, sus alcances y sobre todo sus eventuales perjuicios. El espacio participativo de la consulta les permite pronunciarse sobre las normas para que sus objeciones y reclamos sean escuchados y tengan influencia efectiva en la configuración de la norma. Este proceso procura evitar que las comunidades se afecten en su integridad cultural, económica o social. La sentencia que se profirió en el caso de la ley forestal extendió los alcances del precedente sobre consulta previa porque reconoce la obligación estatal de consultar a las minorías culturales los proyectos susceptibles de afectarlos directamente, antes de su radicación en el Congreso.

\section{OPORTUNIDAD DE DELIBERACIÓN EN LUGAR DE DEBATE CUALIFICADO}

La doctrina sobre elusión deliberativa no hace referencia a la falta de un debate cualificado o al respeto de algún principio sustantivo acerca del tipo o el contenido de las deliberaciones. Ha dicho la jurisprudencia que no es constitucionalmente necesario, para honrar los principios amparados por las reglas procedimentales, que haya una deliberación efectiva en todas las sesiones de debate durante el trámite parlamentario en la que se realice un determinado número de intervenciones a favor o en contra del proyecto $^{48}$. Lo que se resguarda es la esencia del debate que consiste en la prohibición de eludir u omitir la oportunidad de participación que tienen todos los congresistas u

consulta previa, pues varios proyectos son susceptibles de incidir de manera directa y específica sobre pueblos indígenas que residen en las zonas donde serán ejecutados.

${ }^{46}$ Declarada contraria a la Constitución en la sentencia C-030 de 2008.

${ }^{47}$ Declarada contraria a la Constitución en la sentencia C-175 de 2009.

48 Sentencia C-668 de 2004. 
otros intervinientes en el proceso legislativo, así como a la vulneración de los principios constitucionales y aquellos consagrados por el Reglamento del Congreso relativos al ideal deliberativo, tales como la publicitación del proyecto y al período que debe haber entre debates $^{49}$, ambos requisitos para que los congresistas sepan sobre qué trata el proyecto y cuál fue el articulado aprobado en el primer debate para prepararse para los siguientes ${ }^{50}$.

Lo que debe probarse ante el cargo de elusión deliberativa es entonces la omisión de alguno de los requisitos formales relacionados con el trámite, que haya habido discriminación en contra de alguna minoría política o de la oposición al momento de intervenir, que se hayan afectado los principios de consecutividad e identidad, que se haya negado arbitrariamente el uso de la palabra a algún congresista u otro legitimado para intervenir, o que se haya omitido la apertura formal de la deliberación. Si se procede a abrir la sesión de votación sin que se hubiere abierto la de deliberación, acaece un vicio de inconstitucionalidad, por ejemplo. La Corte no exige al Congreso una manera específica de desarrollar la deliberación. El precedente tal como se ha desarrollado según a las sentencias tomadas en la materia, es acerca de oportunidad de deliberación en la sesión de debate parlamentario.

La Corte interpretó el artículo 94 de la Ley 5a de 1992 en el sentido de que la expresión "sometimiento a discusión" en la definición de "debate" no significa deliberación efectiva sino oportunidad libre de intervención regulada solo por normas que establezca el presidente, tal como la duración en el uso de la palabra ${ }^{51}$. Si una norma se somete a discusión y la comisión o plenaria la vota sin que hubiera ocurrido la deliberación, no acontece elusión deliberativa y por lo tanto no se configura un vicio de inconstitucionalidad. No puede la Corte establecer el criterio constitucional de realización efectiva de la deliberación porque un consenso puede surgir en un momento determinado y se vota luego de abierta y cerrada la sesión de debate sin deliberación, sin que ello implique ocurrencia de un vicio insubsanable. La Corte protege que se garanticen las normas constitucionales y orgánicas que regulan el trámite legislativo para que haya oportunidad de deliberar y, de esta forma, resguarda el requisito mínimo de racionalidad deliberativa y decisoria exigido por la normativa orgánica y constitucional ${ }^{52}$.

Esta omisión genera un vicio que se debe analizar en el examen constitucional porque vulnera el artículo 157 constitucional y las normas iusfundamentales que establece la Constitución referentes, principalmente, al principio democrático ${ }^{53}$, al principio de

${ }^{49}$ El objetivo del lapso entre debates es en últimas la garantía del principio democrático para que la decisión no provenga de un impulso irreflexivo sino de la persuasión racional. En sentencia C-203 de 1995 la Corte precisó que incurrir en el vicio de no respetar el lapso entre debates no implica la declaratoria de inconstitucionalidad de la medida, si es posible repetir el segundo toda vez que para los proyectos de ley no se exige su aprobación dentro de una sola legislatura.

50 Tal como lo preceptúa por el artículo 157 constitucional y las normas correspondientes de la ley $5^{\text {a }}$ de 1992.

${ }^{51}$ Sentencia C-714 de 2006.

52 Sentencia C-760 de 2001. APV de Rodrigo Uprimny a la sentencia C-669 de 2004.

${ }^{53}$ Consagrado en los artículos $1^{\circ}$ y $3^{\circ}$ constitucionales. Véase al respecto, sentencia C-089 de 1994. 
democracia participativa ${ }^{54}$ y a la protección a las minorías ${ }^{55}$. El grado de vulneración a estos principios es directamente proporcional al nivel de intensidad del control constitucional a partir de la subregla de elusión deliberativa. Ahora bien, durante el trámite pueden surgir vicios en la formación del proyecto sujeto a control constitucional previo o por demanda de acción pública de inconstitucionalidad, los cuales pueden ser de naturaleza formal o material. Los primeros pueden subsanarse mediante la remisión que del mismo hace la Corte al Congreso, o a la autoridad que lo profirió, para que enmiende el defecto observado. Enmendado, la Corte procede a decidir respecto de la exequibilidad del acto ${ }^{56}$. Este control formal tiene el objetivo de permitir a los ciudadanos, particularmente a quienes conocieron los debates parlamentarios, la oportunidad de plantear ante la Corte las deficiencias en el trámite de un proyecto que en su concepto tengan como consecuencia su inconstitucionalidad. Los segundos no, porque conllevan la inconstitucionalidad de la medida ${ }^{57}$. La vulneración de las garantías constitucionales constituye, conforme al artículo 5 to de la ley 5ta de 1992, "Reglamento del Congreso", uno de los vicios procedimentales insubsanables en tanto se trata de uno de los vicios materiales ${ }^{58}$.

De esta forma, en sentencia C-473 de 2004 se declaró constitucional la ley 812 de 2003 por la que se aprueba el Plan Nacional de Desarrollo 2003-2006. La demanda argüía que se habían vulnerado varios artículos constitucionales ${ }^{59}$, porque no se habían cumplido con las formalidades del procedimiento toda vez que se aceptó y votó una proposición sin suficiente ilustración. Aunque no hayan intervenido todos los congresistas previamente inscritos, no se violan las reglas del debate parlamentario si la deliberación se ha prologando por varias horas y el presidente de la corporación tiene razones fundadas para declarar la suficiente ilustración.

La Corte reconoce que no hay fundamento legal ni constitucional para exigir que las distintas posiciones deliberen bajo determinadas condiciones sustantivas, ni algún grado de profundidad con el que deban analizarse los proyectos sometidos a consideración del Congreso o la satisfacción de parámetros materiales para medir la suficiencia de la deliberación ${ }^{60}$. El margen de acción del legislativo y el respeto a su autonomía, así como la garantía al principio del pluralismo, restringen la intensidad del examen que realiza la

${ }^{54}$ El Preámbulo determina que uno de los fines esenciales del Estado es asegurar "la igualdad, libertad y la paz dentro de un marco jurídico, democrático y participativo”.

55 En este principio se deriva el carácter pluralista del Estado colombiano (art. $1^{\circ}$ constitucional).

${ }^{56}$ Art. 241 constitucional. La sentencia C-737 de 2001 se refiere, igualmente, al tema, aduciendo que este se configura cuando tales vicios recaen o afectan los elementos esenciales de la ley.

57 Sentencia C-614 de 2002.

${ }^{58}$ Los vicios de forma son aquellas irregularidades en que se incurre en el trámite que antecede a la promulgación de la ley. La forma es el modo de proceder de una cosa, la manera cómo se hace; es un concepto que en el ámbito jurídico remite a los requisitos externos de expresión de los actos jurídicos, a las cuestiones rituales que se contraponen a su fondo o materia. Por esta razón los vicios en la formación de la ley se circunscriben a la manera cómo fueron debatidas, aprobadas y promulgadas las disposiciones legales. Sentencia C-501 de 2001.

59 Arts. 150 núm. 3, 151, 157, 160, 339, 341 y 342 constitucionales.

${ }^{60}$ Sentencia C-473 de 2004. 
Corte. La subregla elusión deliberativa es clara en tanto la razón de ser de la normativa reglamentaria y constitucional relativa al trámite parlamentario es determinar las condiciones para garantizar la posibilidad de existencia de un debate democrático.

La precisión acerca de la configuración del margen de acción que la Corte le ha establecido al Congreso en lo relativo a la conducción del trámite legislativo se esclarece en una sentencia importante en la que la fundamentación deliberativa sirvió no para declarar una inconstitucionalidad por elusión de debate sino para avalar la constitucionalidad de determinadas normas. La sentencia que declaró constitucional un artículo de la reforma laboral que presentó el gobierno de Uribe al Congreso, C-038 de 2004, es polémico pero su argumentación es interesante tanto desde el principio de libre configuración legislativa como desde la potestad del Congreso para tomar las principales decisiones nacionales y el criterio de no elusión deliberativa que permitió verificar en el análisis constitucional posterior que en el Congreso no se omitió la consideración de los efectos de la medida acerca de comunidades vulnerables ni se restringió la libre oportunidad de participación de todas las fuerzas políticas.

En las sesiones de debate del trámite parlamentario de la medida se deliberó acerca de la necesidad de disminuir las garantías a los trabajadores porque generaban rigideces en el mercado laboral que son las que, en últimas, explican la magnitud del desempleo, por lo que al reducir las garantías laborales de quienes están empleados en la actualidad se va a aumentar el empleo y, de esta forma, se trataría de una restricción justificada. A nivel técnico se deliberó suficientemente en relación con la posición oficial defendida por el gobierno y por su bancada en el Congreso. De otro lado se sostuvo que ese planteamiento es equivocado porque el problema del déficit de empleo en Colombia no es de tipo neoclásico por costos laborales excesivos, sino que es un déficit más de tipo keynesiano por falta de demanda agregada. Por lo tanto la norma iba, al contrario de lo que sostenían sus defensores, antes que a mejorar el problema del desempleo, a agravarlo.

Cuando acontece un caso en el cual surge una disputa que enfrenta legítimamente a los especialistas en la disciplina desde concepciones y fundamentos que fueron presentados y controvertidos con suficiencia en las sesiones de debate, la Corte en lugar de tomar postura por uno u otro lado de la controversia, debe asegurar el respeto al principio democrático, la inclusión deliberativa de todos los facultados para intervenir en el debate y el control a las restricciones indebidas e injustificadas en derechos fundamentales, sobre todo si se trata de derechos de minorías. Tiene que verificar la fuerza deliberativa en el caso concreto, es decir, que se haya deliberado explícita, razonable y suficientemente respecto de los puntos problemáticos de la medida. La Corte la declaró exequible entre otros argumentos porque verificó el acaecimiento del debate cualificado en el Congreso, en virtud del cual no solo las mayorías sino incluso y particularmente las minorías intervinieron en igualdad de condiciones y tuvieron la oportunidad de contribuir a la configuración de la medida al argumentar frente a quienes lideraban la propuesta acerca de sus potenciales efectos perjudiciales.

La Corte procede entonces adecuadamente sin zanjar con un fallo una discusión compleja, en este caso de economía pública. Por falta de clarividencia no puede ser juzgado un tribunal, ya que efectivamente como sostenían los críticos la medida no tuvo 
los efectos esperados en términos de estímulo al empleo. A partir del margen de acción configurado para el Congreso en el trámite de los proyectos y del concepto procedimental de democracia deliberativa, se concibe como adecuado el proceder de la Corte en este caso. A partir de este fallo se puede deducir que para la Corte la deliberación acentuada puede justificar constitucionalmente la restricción de derechos. En casos como este la Corte afirma que un debate acentuado puede permitir hacer cosas que un debate mínimo no. Si una medida va a limitar o restringir un derecho o una garantía, su votación debe al menos estar precedida por una amplia discusión cualificada.

Lo que debió haber hecho, en lo que se constituye una crítica al precedente establecido, es no declarar la cosa juzgada permanente en este, así como en otros casos en los cuales las medidas que restringen derechos están fundamentadas en una de varias teorías económicas posibles. En efecto, si en un tiempo prudencial se verifica que la norma no alcanzó razonablemente el fin propuesto con el medio elegido, cuyos efectos negativos sobre los derechos o sobre las expectativas de las personas sí se comprobaron, debe declararse inconstitucional. Por muy constitucionales que sean los fines que se pretenden alcanzar, la norma se torna palmariamente irrazonable si el medio elegido para conseguirlos no lo hace pero sí afecta derechos, es decir, no tiene los efectos positivos esperados pero sí tiene efectos negativos previstos. En casos difíciles entonces cuando gracias a la deliberación cualificada se determina que aquello que permite considerar proporcional la restricción de derechos es el impacto positivo de una medida legislativa, se debería declarar que la cosa juzgada no es permanente sino hasta cuando dicho impacto se verifique.

\section{BIBLIOGRAFÍA}

Alexy, R., Teoría de los derechos fundamentales. Madrid, CEPC, $2^{\mathrm{a}}$ ed., 2007.

Bellamy, R.; Castiglione, D. (eds.), Constitutionalism in Transformation: European and theoretical perspectives. Oxford, Blackwell, 1996.

Carbonell, M.; García Jaramillo, L. (eds.), El canon neoconstitucional. Bogotá, Universidad Externado, 2010; $2^{\mathrm{a}}$ ed., Madrid, Trotta, 2010.

Cohen, J., “An Epistemic Conception of Democracy”, en Ethics, Vol. 97, N 1, 1986.

Estlund, D., "Beyond Fairness and Deliberation: The Epistemic Dimension of Democratic Authority", en Bohman, J.; William, R. (eds.). Deliberative Democracy. Essays on Reason and Politics, Cambridge (Mass.): MIT Press, 1997.

Gaus, G., "Looking for the best and finding none better: the epistemic case for deliberative democracy", en The Modern Schoolman, Vol. 74, 1997.

Habermas, Jürgen, "Justicia y legislación: sobre el papel y legitimidad de la jurisprudencia constitucional”, en Facticidad y validez. Madrid, Trotta, 1998.

Landau, D., "Political Institutions and Judicial Role in Comparative Constitutional Law", en Harvard International Law Journal. Vol. 51, Nº 2, 2010.

LANDAu, D., Derechos sociales y límites a la reforma constitucional: la influencia de la jurisprudencia de la Corte Constitucional colombiana en el derecho comparado. Bogotá, Universidad Externado, 2015.

LEwIn Figueroa, A., Evolución de la jurisprudencia de la Corte Constitucional en materia tributaria (1992-2005). Trabajo de posesión como miembro correspondiente de la Academia Colombiana de Jurisprudencia. Bogotá, noviembre 10 de 2005. 
Mac Cormick, N.; Summers, R. (eds.), Interpreting Precedents: A comparative study. Dartmouth, 1997.

Mendes, Conrado Hübner, Constitutional Courts and Deliberative Democracy. New York, Oxford University Press, 2013.

Nino, C.S., The Constitution of Deliberative Democracy. New Haven, Yale University Press, 1996. Vers. cast. de Roberto Saba, La constitución de la democracia deliberativa. Barcelona, Gedisa, 1997.

Noguera Fernández, Albert; Criado de Diego, Marcos, "La Constitución colombiana de 1991 como punto de inicio del nuevo constitucionalismo en América Latina”, en Estudios SocioJurídicos, Vol. 13, N 1, Bogotá, Universidad del Rosario, 2011.

Nolte, D.; Schilling-Vacaflor, A. (ed.), New Constitutionalism in Latin America. Promises and Practices. London, Ashgate, 2012.

ReHG, W., "Legitimacy and Deliberation in the Epistemic Conception of Democracy: Between Estlund and Habermas”, en The Modern Schoolman. N ${ }^{\circ}$ 74, 1997.

Rosenkrantz, C., “The Epistemic Theory of Democracy Revisited”, en H. H. Koh; R. Slye (eds.). Deliberative Democracy and Human Rights, New Haven: Yale University Press, 1999.

Sunstein, Cass, Designing Democracy. What constitutions do. Oxford, Oxford University Press, 2001.

Thompson, D., "Deliberative Democratic Theory and Empirical Political Science”, en Annual Review of Political Science, Vol. 11, 2008.

Young, I.M., “Activist Challenges to Deliberative Democracy”, en Political Theory, N 29, 2001. 